\title{
Teaching English in Hong Kong Kindergartens: A Survey of Practices
}

Mei Lee NG, The Hong Kong Institute of Education, Hong Kong

Nirmala RAO, The Hong Kong University, Hong Kong

Abstract

The teaching of English to very young learners has become popular across the Asia Pacific region, and Hong Kong is no exception. This trend is believed to be driven by socio-economic forces rather than by educational research since there is a dearth of empirical research in this area. This paper draws on data from a questionnaire which was part of a larger study to portray systematically the school contexts in which the teaching of English took place. The principals of 38\% (n=256) of the local registered kindergartens in Hong Kong responded to questions about English instruction time, teachers' professional qualifications, curriculum activities and the school language environment. The results indicated that English was taught in most of the kindergartens as a specific subject, following a textbook-based approach. It was taught for an average of 64 minutes per week in programmes featuring half-day sessions. The teachers' professional backgrounds, the allocation of instruction time, and the curriculum planning practices were diverse, implying that there was a large gap between the classroom instruction and the contextual support and guidelines. This gap should alert practitioners, parents, and policy makers to the fact that the perceived head start effect of teaching English early cannot be taken for granted. The intricate interaction between global forces, policy implementation and micro-level practices at the school level are also discussed and extrapolated.

Keywords: Teaching English to young learners, English as a foreign language, Kindergarten education 


\section{Introduction}

$\mathrm{T}$ he English language has become dominant in this era of globalisation and increasing international contact and exchange. The effect of these global forces on education is manifested in the increasing number of primary school children who are learning English as a foreign language in schools. There has been a concomitant increase in research on the early teaching of foreign languages in a number of European countries (Blondin et al., 1997; Edelenbos, Johnstone and Kubanek 2006; Nikolov and Curtain 2000). Teaching English as a foreign language in kindergarten has become popular in many parts of the Asia-Pacific region, including mainland China, Taiwan, and Hong Kong (Adamson 2010; Lu 2002; Chang and Chang 2001; Ruan 2002; Lu 2010; Wu 2007).

This trend is more driven by socio-economic forces than supported by any educational research. The instrumental value of English is strongly felt by parents who regard the learning of English as a path to upward social mobility and better educational and career opportunities. This belief is shaped by societal values and educational policies (Li 2009; Tsui 2004). Parents are anxious to give their children a head start in English so that they can get into prestigious primary schools, which usually set high English standards for admission. Hence, parents want their children to receive some English education in kindergarten. As nearly all of the kindergartens in Hong Kong are in the private sector, parents' needs and expectations are the major market force shaping the kindergarten curriculum. Furthermore, the drastic drop in the birth rate from 16.8 per 1,000 in 1981 to 7.1 in 2004 (Census and Statistic Department 2007), has intensified competition among kindergartens, which have responded by making curriculum decisions in response to parental demands. In May 2000, the Education Department surveyed 491 kindergartens (about $50 \%$ of the total number), and found that over $97 \%$ of them provided some form of English instruction. This was occurring even before English teaching was officially addressed in the Guide to the Pre-primary Curriculum (The Curriculum Development Council 2006). These statistics illustrate the popularity of teaching English in kindergarten and reflect parental demands.

Despite the popularity of teaching English in kindergarten, there is a dearth of empirical research that documents the pervasiveness of English teaching, characteristics of the teachers, and implemented pedagogical practices. Sporadic surveys were conducted by the Education Bureau (formerly known as the Education and Manpower Bureau, EMB) in 2003, and by Lim and Li in 2005. The survey conducted by the EMB found that $55 \%$ of the surveyed kindergarten teachers used textbooks to teach English in a very formal manner. Most of the textbooks used were developed by commercial publishers and usually contained discrete language items rather than interactive language activities. Writing and drilling exercises increased from lower to upper kindergarten in $32 \%$ of the kindergartens surveyed (EMB 2003). A survey conducted by Lim and Li (2005) found that English teaching was generally formal. There was a diverse range of practices, from employing native English speakers (NETs) to using local teachers, or both. The frequency of English language activities ranged from two to three times per week to four to five times. The duration of each session ranged from 20 minutes to an hour. Yet, these studies are neither current nor comprehensive. The EMB survey was done in 2003 and the response rate to the survey conducted by Lim and Li was rather low due to the outbreak of Severe Acute Respiratory Syndrome (SARS) and the subsequent closure of schools for a few months that occurred in 2005. 
The aim of this paper is to draw on survey data that were collected as part of a larger study to portray the various contexts within which the English teaching in Hong Kong kindergartens took place. The survey data set was used, in particular, to examine whether the existing practice was supported adequately by desirable conditions for language learning.

\section{Optimal conditions for English language learning}

Previous studies have shown that the availability of desirable conditions, rather than an early start, is the key to success in children's foreign language learning (Edelebenbos et al. 2006; Moon 2005; Nikolov and Curtain 2000; Singleton 2003 ; Rixon 2000). Specific features of the learning context, such as teachers' characteristics, instruction time, curriculum and pedagogies, and language environment, have been identified as essential conditions affecting the teaching and learning of English to young learners.

Edelenbos et al. (2006) conducted a study of children learning a foreign language in classroom settings and affirmed the central role of the language teacher in providing target language input, facilitating target language interaction, and helping children acquire metalinguistic or intercultural knowledge. The study found that teachers who were proficient in both the L1 and the L2 and could apply age-appropriate methodology successfully were essential to effective and useful foreign language programmes (Blondin 1997; Bondi 2001; Moon 2005).

Moon (2005) listed the essential qualities of teachers who were teaching English to young learners. He grouped them into two large categories: (1) knowledge of the language and its pedagogy, and (2) knowledge of children's cognitive, linguistic, and emotional development. Teachers with good English language skills can provide the main language input to children who may have very limited exposure outside the classroom. Teachers with knowledge of child development know how to gauge age-appropriate teaching strategies to cater to the developmental characteristics of young children. Moon (2005) suggested that both professional English teaching training (TESL) and early childhood training (ECE) are desirable qualifications for an English teacher for young learners.

Another characteristic of English teachers discussed in the literature is the significance of their native tongue. Research supporting the use of NETs has noted that they can offer "breadth of active vocabulary, can use appropriate idiom, harness intuition about usage and provide an insider's cultural knowledge, [and] provide a need for students to engage in authentic English use" (Barratte and Knotra (2000) as cited in Carless and Walker 2006, 463). Meanwhile, the weaknesses of NETs in anticipating language difficulties and in making profitable use of the mother tongue have often been used to challenge the benefits of their use. Research has not confirmed the inherent superiority of NETs over non-native speakers (Medgyes 1994 and Tang 1997 as cited in Carless and Walker 2006, 464). It is still doubtful if the identified advantages of using NETs to teach older children also apply to young children. Nevertheless, parents generally prefer NETs to local teachers in the kindergarten English classroom.

Blondin et al. (1997) clearly highlighted the importance of the amount of time allocated to learning a foreign language. In their extensive review of the research on foreign language programmes for young children, Edelenbos et al. (2006) concluded that of the four language skills, speaking skills appeared to suffer the most 
when instruction time was limited. Met and Rhodes (1990) argued that the overall amount of time given to foreign language learning at primary levels, along with how often children received lessons in a week, were critical factors affecting language learning.

Empirical studies have also suggested that the specific effect of 'time of learning' was clearest only in combination with other contextual factors related to the quality of teaching, such as an age-appropriate curriculum and a rich English language environment (Edelenbos et al. 2006, 24). Previous research on early childhood education has found that young learners' specific developmental characteristics can best fit into a play-based curriculum with interactive activities that focus on meaning rather than on form. In addition, a rich language environment at school was found to be beneficial to learning as it increases the learner's exposure to the target language in a foreign language context.

\section{The survey}

The aim of the present study was to provide a comprehensive portrayal of the teaching of English and the conditions within which it took place. Kindergarten principals were surveyed to answer the general research questions: (1) What are the English teaching practices in kindergarten settings? and (2) How do these practices relate to the contextual conditions? The questionnaire items were designed around four essential contextual conditions for language learning as informed by the extant literature: (1) teacher characteristics (e.g., nationality, native tongue, professional qualifications and training, years of experience"), (2) instruction time (e.g., duration and frequency of English lesson), (3) learning activities and materials (e.g., types and frequencies of learning activities, types and frequencies of material use), and (4) language environment at school (e.g., presence of English corner, how the English corner is used) (see Appendix)

\section{Sampling}

In May 2008, questionnaires were sent by post to 684 of the 988 privately run local preschools (kindergartens and kindergartens-cum-childcare centres serving 3-6-year-olds) registered with the Education Bureau (formerly known as the EMB).

Local preschools are schools that adopt Chinese as the medium of instruction and serve local children, who are mostly Cantonese-speaking, whereas international kindergartens use English as the medium of instruction and have a very different curriculum from those of the local schools. This study focused on the local schools.

Local preschools are classified according to their curricula and the ages of the children they serve: (1) kindergartens, (2) kindergarten-cum-childcare centres, and (3) childcare centres. Kindergartens and kindergarten-cum-childcare centres have similar curricula that are more academically oriented than those of childcare centres. Hence, they were sampled for the survey.

\section{Results}


Thirty-eight per cent of the questionnaires $(n=256)$ were returned. They were completed by principals or head teachers. Consistent with the findings of previous surveys (EMB 2003; Lim and Li 2005), all of the sampled kindergartens (100\%) offered English teaching at the K2 and K3 levels (ages 4 and 5, respectively), and the percentage of K1 (age 3) classes offering English was 97.3\%. Most of the respondents (99.1\%) reported that Cantonese was the main medium of instruction (CMI) for classroom activities, and that English teaching was offered in specific daily or weekly time slots. Diversity was the dominant pattern in the four contextual conditions for foreign language learning.

\section{Diversity in Teacher Characteristics}

The sampled schools reported that their English teachers were of diverse national and professional backgrounds, including teachers who spoke English as their first language, non-Chinese teachers speaking English as a second language, returnees from foreign countries, local or mainland Chinese teachers with an English major, and local early childhood teachers (see Figure 1).

Figure 1. National and professional backgrounds of English teachers

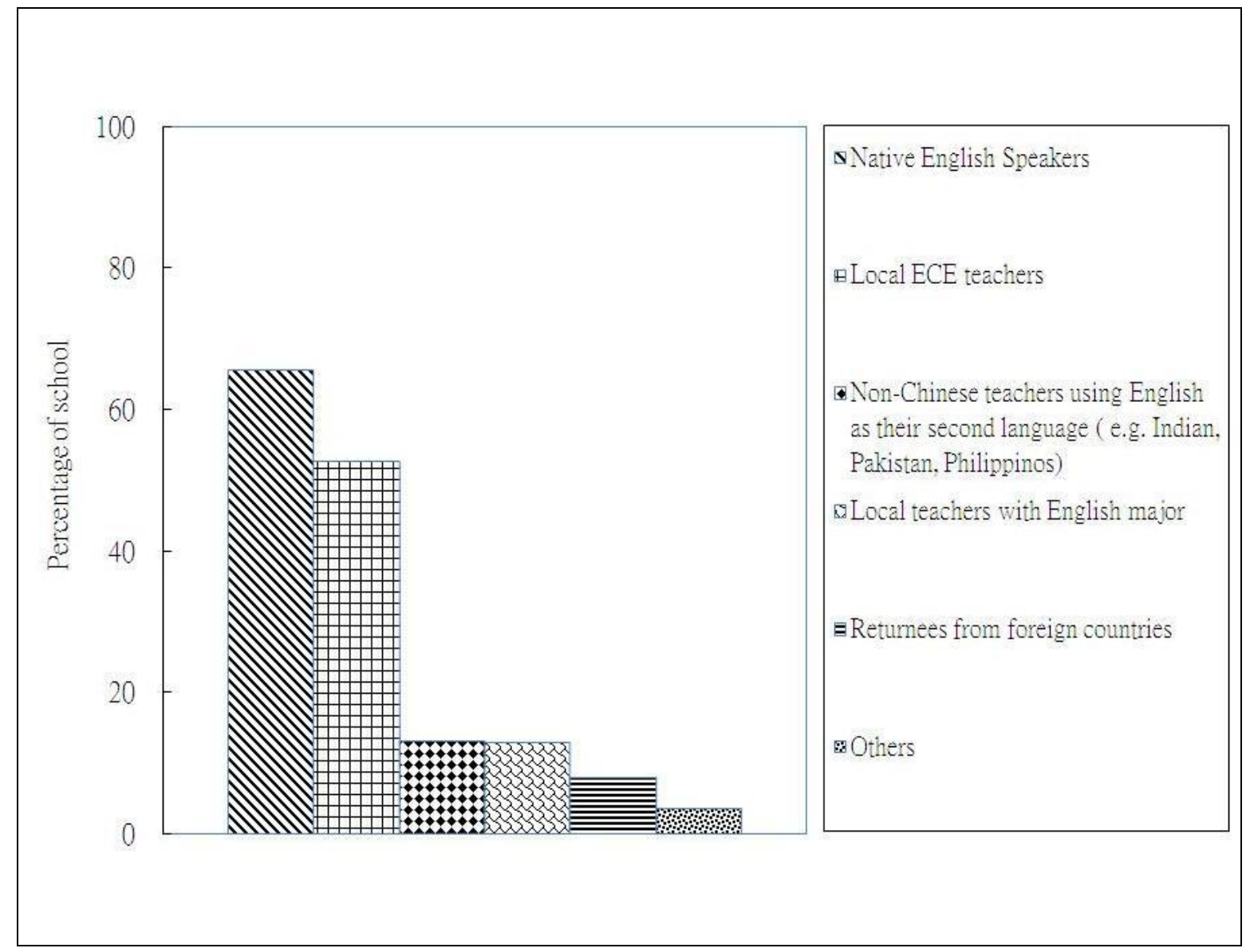

The fact that NETs were the dominant group confirms the previously identified general preference of parents. However, the data also shows that local non-native speakers were included in the teaching force, which may suggest that NETs alone could not meet the expanding need for English teachers. 
With regard to the professional profiles of the English teachers, only $15.2 \%$ of the surveyed schools reported having English teachers who had been trained professionally in both English teaching and early childhood education. A similar percentage of schools (13.7\%) reported that they had untrained English teachers (see Figure 2). More schools reported having ECE-trained teachers than TESL-trained teachers. Obviously, the ECE-trained teachers were local teachers who had been co-opted to teach English due to the expanding and pressing demands from parents for English teaching in kindergartens.

Figure 2. Teachers' professional qualifications

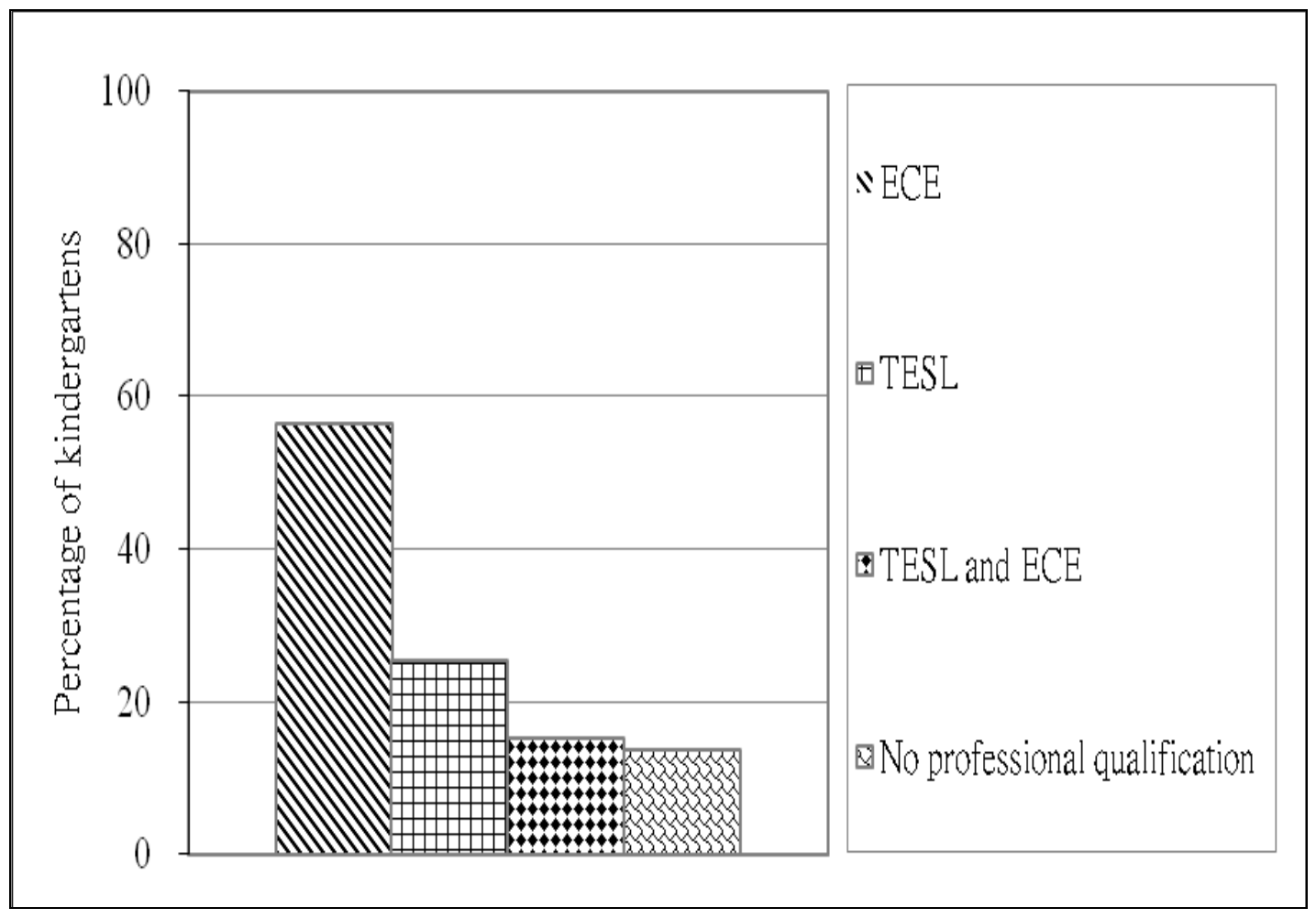

Consistent with the teachers' relatively low professional qualifications, the percentage of those who had received relevant English teaching training from any source was also low. In fact, $29.4 \%$ of the schools reported having teachers who had not received any on-the-job training in English teaching (see Figure 3). Only a small percentage of the schools $(14.8 \%)$ indicated that their teachers had received training from the Standing Committee on Language Education and Research [SCOLAR], which had already launched the pilot planning stage of the Quality English Language Education at Pre-primary Level Project when this study was conducted. 
Figure 3. Training in English language teaching

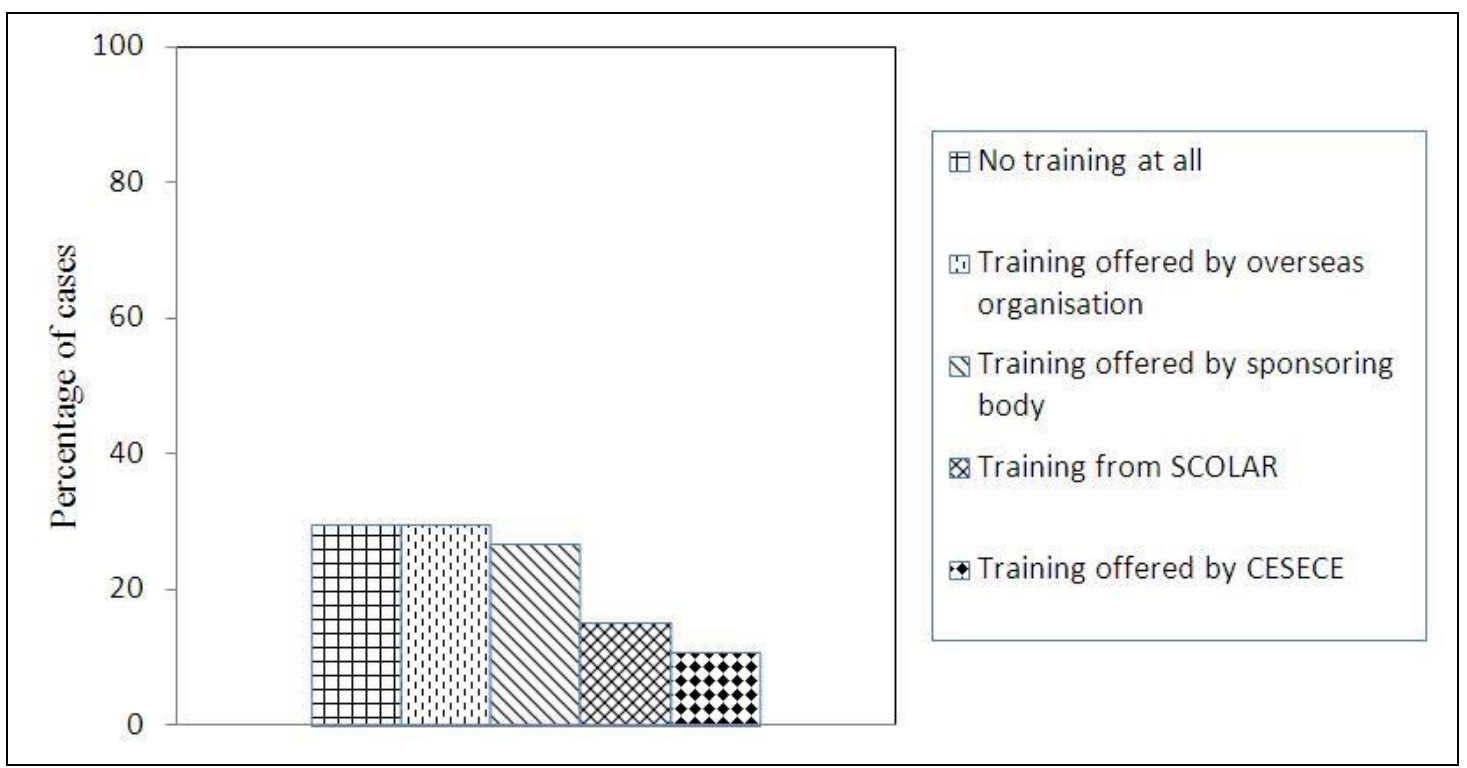

\section{Diversity in Instruction Time}

Schools running half-day sessions reported a wide range of instruction time (from 15 minutes to 536 minutes per week) allotted to English learning in the upper levels (K3) (see Figure 4).

Figure 4. Half-day K3 - English instruction time per week

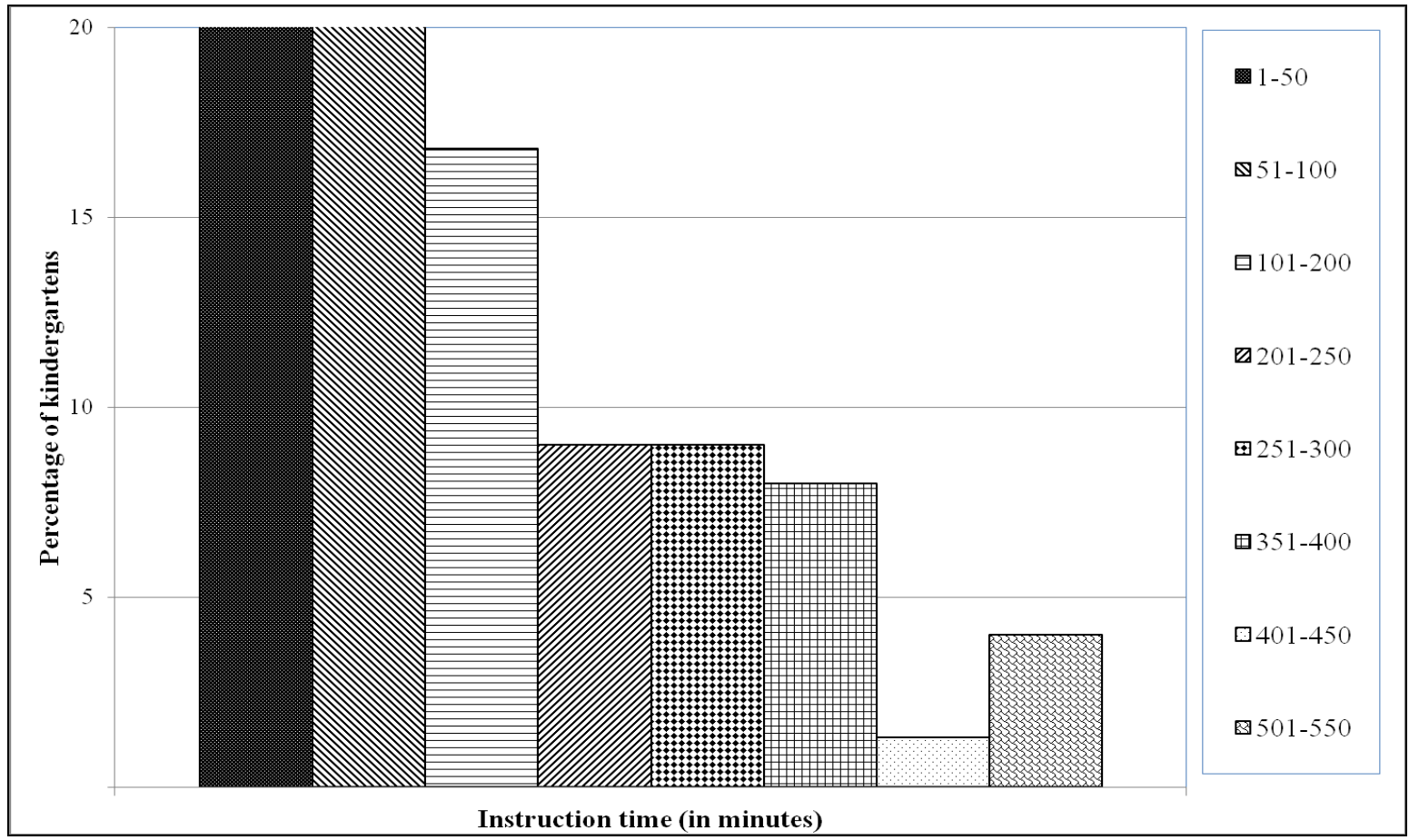

Interestingly, the variation among schools in instruction time was found to be related to financial factors.

The English instruction time allocated to K3 classes was significantly correlated with the school fees charged by 
the schools $(\mathrm{r}=.43, \mathrm{p}<.01)$. That is, schools charging higher school fees tended to allocate more instruction time to English. Hence, schools' allocation of instruction time was not determined by any official guideline or informed by research. Instead, the decision was related to financial considerations. It is likely that schools charging higher fees could afford to hire more specialist English teachers, usually native speakers, and could pay them to teach more frequently during the week.

The variation in instruction time was also found to be related to the reported class activities. The total English time allotted was found to be significantly correlated with the story-book activities reported $(r=.28$, $\mathrm{p}<.01)$. In other words, schools with more time allocated to English instruction reported more frequent use of story-book activities in class.

Despite the diversity in the amount of total time that schools allocated to English teaching, the median duration of English instruction was found to be relatively limited. The median duration of English lessons for half-day K3 classes was only 72.5 minutes per week, out of a total of 900 minutes of school time (i.e., $8 \%$ of the total school time). This was less than half (17\% to $21 \%)$ of the average lesson time in primary school settings (CDC 2003, 111).

Schools running half-day sessions faced more constraints in allocating instruction time for English (see Figure 5). One major constraint came from the need to teach three languages, Chinese, Putonghua, and English; 92.7\% of the responding schools reported that they offered Putonghua lessons in K3, with the average duration of Putonghua lessons being 44.5 minutes per week. With the launch of the government's trilingual and biliterate policy (Education Commission 2004), schools offering trilingual programs (English, Chinese, and Putonghua) were able to attract more students. The local kindergartens were packed with a variety of subjects, each of which was offered for a relatively limited instruction time and in a compartmentalised manner.

Figure 5. Weekly English instruction time in half-day kindergartens (K3) 


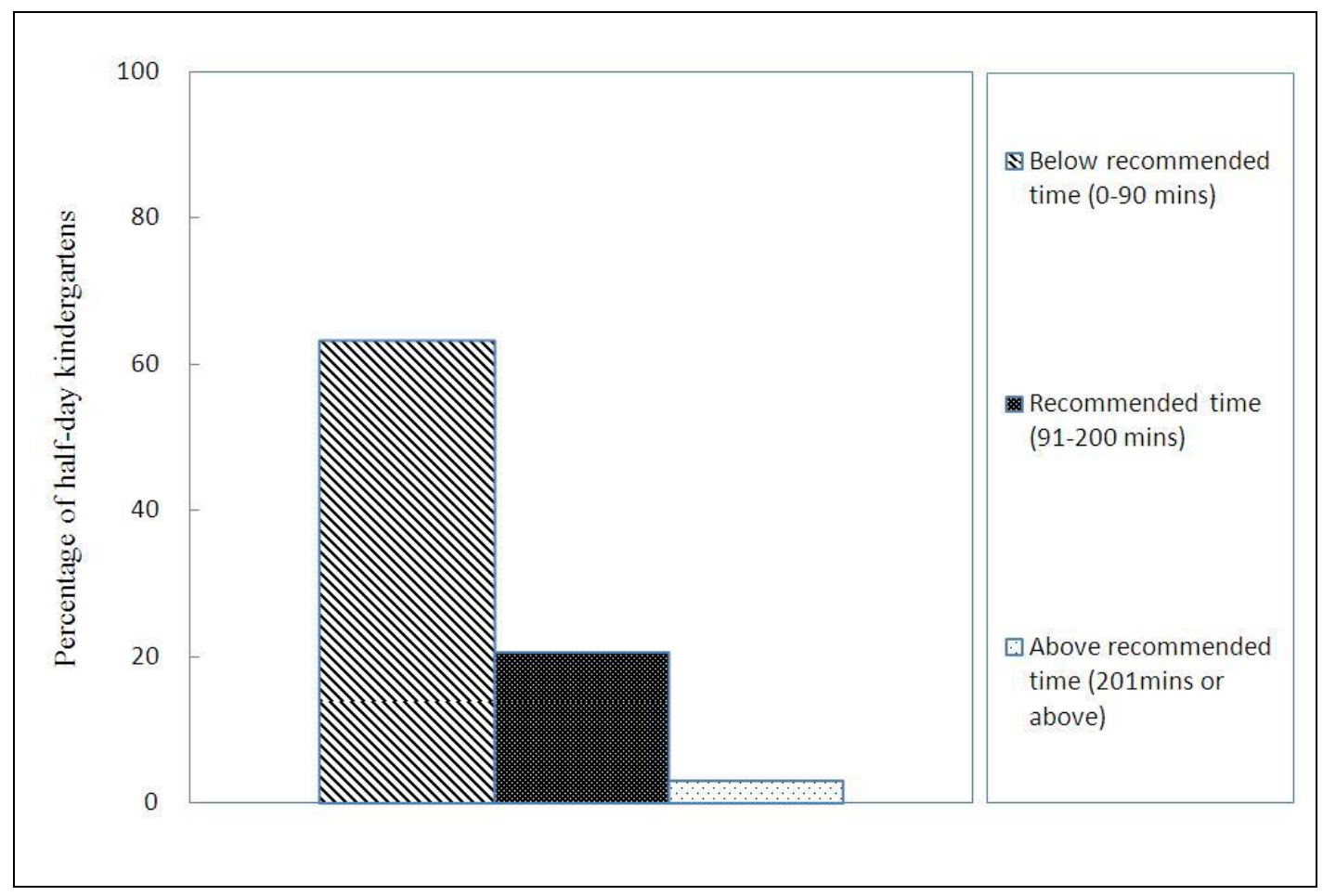

\section{Diversity in Curriculum Planning Practices}

In addition to the diversity found in instruction times and teachers' nationalities and professional qualifications, there was diversity in how the English curriculum was chosen. The following practices were reported: (1) decided by the curriculum teacher $(33.3 \%)$, (2) decided by both the NETs and the local English teachers (32.2\%), (3) decided by the NETs only (30.2\%), (4) decided by the principal (28.6\%), or (5) followed the commercial English Language teaching [ELT] package (21.6\%).

This diversity was partially a reflection of the exploratory stage of the English curriculum in kindergartens, and partially due to the lack of official support for the curriculum. The existing Guide to Pre-primary Curriculum (CDC 2006) contains only one page of practice guidelines for second language learning. The guide states how English should be taught, but does not explain why (the rationale), what (the curriculum content), or what will happen (the expected learning outcomes) if English is learnt in kindergarten. In contrast, the English Language Curriculum Guide (The Curriculum Development Council 2004) for the primary sector provides a comprehensive curriculum framework with the aims, learning targets, objectives, principles in curriculum planning and management, learning and teaching strategies, sample learning and teaching resources, and a clearly delineated assessment guide. This absence of official support can be explained easily by the fact that kindergartens are not yet included in the formal education system.

\section{Learning Activities and Homework}

About $72.4 \%$ of the survey respondents said that they still used textbooks frequently and that the traditional paper and pencil exercises still occupied a dominant position in classroom assignments and homework. The tendency to assign written English work was consistent with the reported English learning activities in the 
classrooms. Formal exercises, such as copying words and sentences, were found to be slightly more dominant than activities such as singing, reading stories or playing games. The copying of words and sentences was performed two to three times a week in $86 \%$ of the schools. This copying practice has been documented in previous surveys. Nearly $50 \%$ of the surveyed kindergartens assigned writing exercises and $32 \%$ increased the writing and drilling exercises from lower to upper levels (EMB 2003). Although story-book reading was accepted as appropriate homework for English learning, more creative types of activities, such as story-book making, were still not common (see Figure 6).

Figure 6. Forms of English work assigned

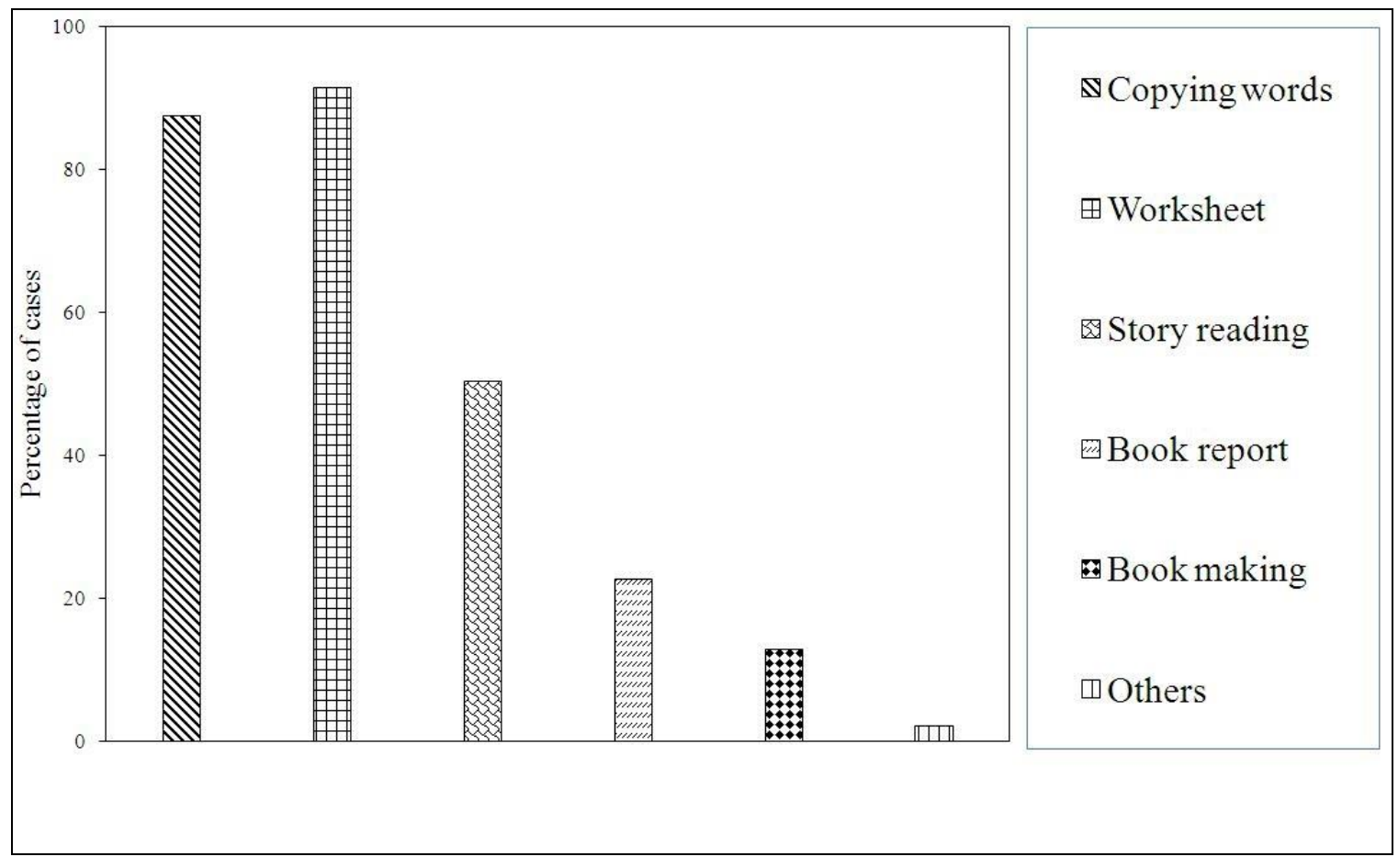

The data reveal a conflict between what happened in the classrooms and the Guide to Pre-primary Curriculum $(2006,29)$

Language activities have to meet children's developmental needs. Any teaching approach that is overly bound by chosen texts or strenuous written exercises should be avoided. Rote-learning or dictation should not be adopted. Otherwise, children's interest in learning English will be weakened because of the pressure. (p. 29)

The fact that these practices existed both before and after the Curriculum Guide was published suggests that the practices stated in the guide were undesirable practices that were prevalent in the field, rather than a set of directives developed to guide teachers.

The copying practice may remain common, despite these recommendations, due to a deep-rooted belief that the formal approach to learning English prepares children for primary school (Pearson and Rao 2006). The influence of the Chinese way of learning might also account for such a practice. Tan et al. (2005) noted that the visual-orthographic demands of written Chinese necessitate what has become a prevalent strategy for teaching 
children to learn to read, namely asking them to repeatedly copy samples of single characters. Without much knowledge of how English should be taught, practitioners have tended to transplant the familiar strategies they use to teach children Chinese into the teaching of English for young children.

Previous studies of Teaching English to Young Learners have claimed that children benefit more from meaning-focused activities and opportunities to speak the language than from form-focused activities. If the claim is valid, the drilling and copying practices revealed in the survey data may not provide desirable learning experiences for young children who do not have much English exposure outside the classroom.

\section{Diverse Use of Bilingual Environment}

More than half (65.6\%) of the surveyed kindergartens reported that they had separate English corners in their classrooms. However, the materials displayed in the corner were as diverse as the corners' uses, which included self-learning, teaching English, displaying English materials, and sorting English materials (see Figure 7).

Figure 7. Use of English corner

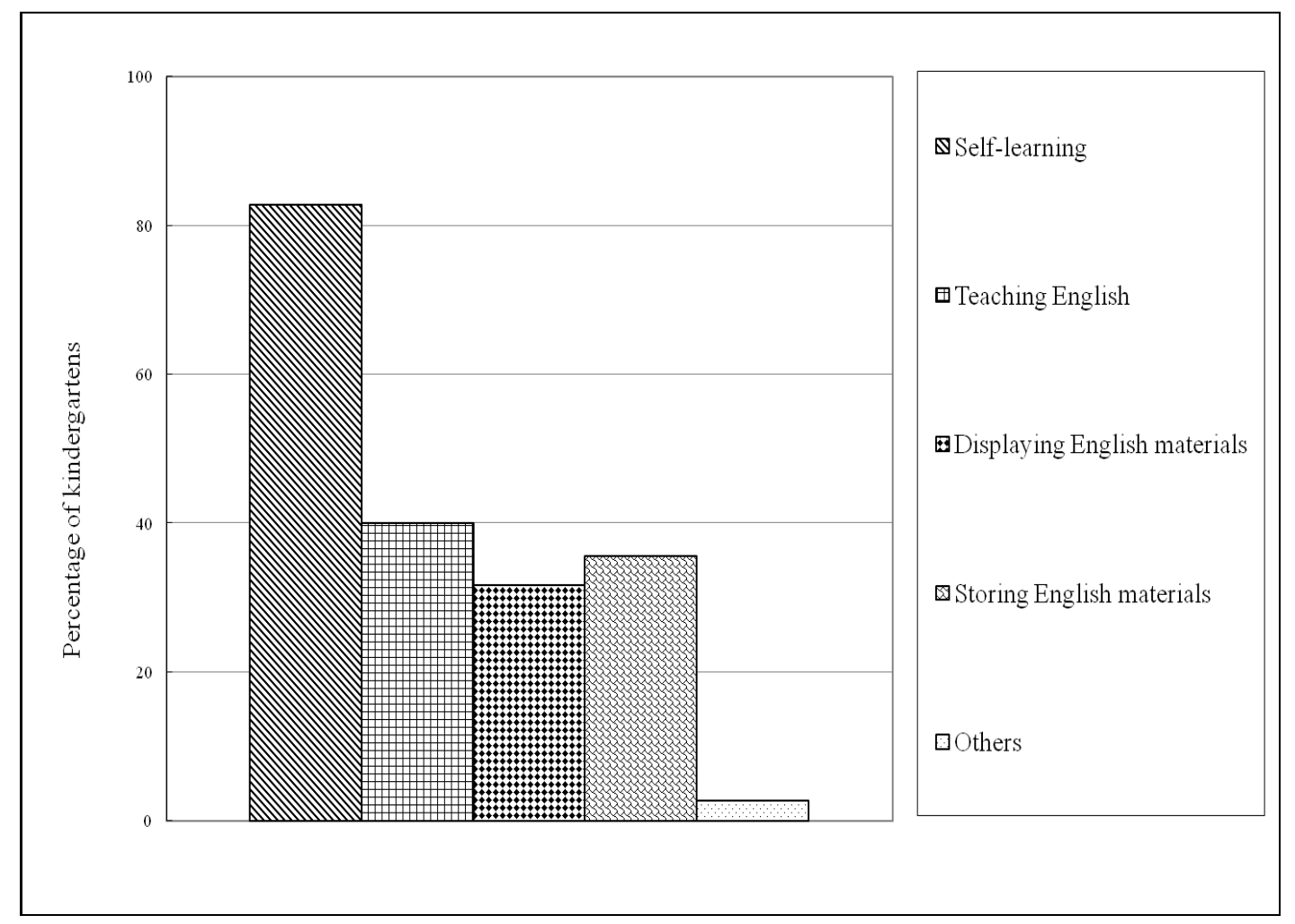

The frequently reported presence of English corners and English storybooks indicates a bilingual environment in many schools, providing English language input for children. However, the various uses reported suggest that there was no consensus among the sampled schools about the functional purpose of a bilingual environment. Again, there was a lack of guidelines about how the environment might be used strategically to enrich children's learning. 


\section{Discussion}

This study confirmed the pervasiveness of English teaching in Hong Kong kindergartens and the accompanying diversity in the teachers' professional backgrounds, the allocation of instruction time, the decisions about curriculum planning, and the use of bilingual environments in schools. These findings highlight several challenges, which are discussed below.

\section{Challenge of Ensuring Equal Access to Quality Programmes}

The diversity in practices may be accounted for by an absence of official guidelines that specify what, who, how long and how much to teach in the early years. The absence of specific guidance may be due to the lack of research on the best practices and to the fact that kindergartens are excluded from the formal education system. Hence, individual kindergartens tend to make their own decisions about practices. The results from this survey indicate that decisions about who, what, how much and how long to teach are very often related closely to financial or resource considerations rather than to educational concerns. For example, among the surveyed schools there was a positive correlation between the school fees and the English instruction time allocated to K3 classes; likewise between school fees and teachers' professional qualifications and between instruction time and the frequency of story book activities. Schools with more resources may be better equipped to hire qualified English teachers, whereas those with fewer financial resources may have less qualified teachers and allocate less time to English instruction. This inequality in the provision and support for the teaching and learning of English was also mentioned by Cameron (2003), in his discussion of the expansion of teaching English to young learners. The issue of equal access to quality English among children from different socio-economic backgrounds requires further research.

\section{Challenge of Improving English Teacher Training}

The essential role of the teacher in supporting children's second language acquisition in the classroom setting has been established clearly. One of the essential conditions of effective language learning in kindergartens is to attain teachers who have training in both ECE and TESL (Lu 2002). Therefore, the fact that only $15 \%$ of the schools had teachers with qualifications in both ECE and TESL, and that $13.5 \%$ of them had totally untrained English teachers, is an issue that warrants the attention of policy makers.

The training issue is both challenging and complicated. As the survey shows, NETs are still the dominant group. Should basic qualifications be required for NETs who are now taking up the teaching of English in kindergartens? Should they have priority over the non-native speakers who are ECE trained? The issue is complicated further by the fact that most of the NETs are provided by private language agencies and centres, and they work at the schools on a part-time basis. To train part-time NETs in ECE would have huge resource allocation implications. Policy makers may find it advisable to enable kindergartens to hire NETs as full-time teachers, as in local primary and secondary schools, so that the kindergarten NETs will be governed by the stipulated regulations; this will ensure that they are trained properly, not only in teaching English, but also in early childhood education. 
Changing the NETs from a part-time to full-time status has many resource implications, and may be feasible only if kindergartens are removed from the private sector and included in the formal education system. Before this can happen, the training of local non-native teachers is a good alternative, although parents' would need to be re-educated about the relative value of the NETs.

\section{Challenge of Creating a Unique Second Language Curriculum for Kindergarteners}

There are great challenges involved in creating kindergarten curricula that can accommodate English teaching together with Putonghua and a number of other pre-academic subjects in the tight schedule of a half-day session. Moon (2005) argued that we cannot expect any substantial gains in language learning if children have such limited exposure to the second language. Parents need to be awakened from the myth that, by placing their young children in a half-day kindergarten with English taught once a week, the children can become proficient early speakers of English.

The survey findings reveal a disparity between what has been promoted in the Curriculum Guide and what has been practiced in the field. The current curriculum guide is not adequate in supporting the teaching of English as a foreign language. A more detailed curriculum, with a research-based framework, would improve the teaching of second languages in kindergarten settings.

\section{Conclusions}

This study has provided a broad overview of the contexts in which English language teaching in local kindergartens took place. The gap between the demand for English classes in kindergartens in Hong Kong and the inadequate contextual support has revealed, to a certain extent, the interaction between global forces, policy implementation and school practices at the micro-level.

The survey data contribute significant and updated knowledge to the field while, at the same time, highlighting the challenges faced by policy makers in seeking to ensure equal access to quality English teaching, better teacher training, and a unique early childhood foreign language curriculum and pedagogy. However, it is clear that the survey also had inherent limitations in providing detailed information about how these diverse practices affect learning in the classroom. The gap has to be filled by qualitative classroom studies, this being the second stage of enquiry and beyond the scope of this paper to report. Further research is required in this under-explored area of teaching children English, not only in Hong Kong, but also in other Asia Pacific areas that have similar foreign language contexts.

\section{Funding}

This work was supported by an HKIED-Internal Research Grant [grant number R3174]. 


\section{ABOUT THE AUTHORS}

Dr. Mei Lee NG : Dr. Ng is Assistant Professor of Department of Early Childhood Education, The Hong

Kong Institute of Education. She combined her specialism on Teaching English as A Second Language and Early Childhood Education to develop her particular interest in researching preschoolers' second language teaching and learning.

Dr. Nirmala Rao : Dr. Rao is Professor of Faculty of Education, The University of Hong Kong. She is a Developmental and Chartered (Educational) Psychologist, recognized internationally for her work on early childhood development and child development and education. Her research program concerns the influences of home and preschool experiences on early child development and the policies which affect them. 


\section{REFERENCES}

Adamson, Bob. 2010. "English for Young Learners in Mainland China and Hong Kong: Opportunities and Dilemmas." Paper presented at the International Conference on Teaching and Learning of English for Children in Early Years in the Asia-Pacific Region, Hong Kong, May 28-29.

Blondin, Christiane, Michel Candelier, Peter Edelenbos, Richard Johnstone, Angelika Kubanek-German, and Traute Taeschner. 1997. "Foreign Languages in Primary and Pre-school Education: Context and Outcomes. A Review of Recent Research within the European Union.” London: CiLT. Accessed February 2, 2011. http://ec.europa.eu/education/languages/archive/key/foreign_en.html.

Bondi, Marina. 2001. "Towards a Language Profile for the Primary Foreign Language Teacher." In Effective Foreign Language Teaching at the Primary Level: Focus on the Teacher, edited by Manuel Jiménez Raya et al., 39-50. Berlin: Peter Lang.

Cameron, Lynne. 2003. “Challenges for ELT from the Expansion in Teaching Children.” English Language Teaching Journal 57(2):105-112.

Carless, David, and Elizabeth Walker. 2006. "Effective Team Teaching between Local and Native-speaking English Teachers." Language and Education 20(6): 463-477.

Census and Statistics Department. 2007. Demographic Trends in Hong Kong, 1981-2006. Hong Kong: Hong Kong Government.

Chang, Shiang-Jiun, and Chien-Ju Chang. 2001. “幼稚園實施外語課程及聘僱外國籍教師從事外語教學之可 行性” [The feasibility of implementing a foreign language curriculum and hiring NET teachers to teach English in kindergarten]. Education Commission Report. (In Chinese)

Edelenbos, Peter, Richard Johnstone, and Angelika Kubanek. 2006. "The Main Pedagogical Principles Underlying the Teaching of Languages to Very Young Learners: Languages for the Children of Europe. Published Research, Good Practice and Main Principles. Final Report of the EAC 89/04, Lot 1 Study." European Commission. Accessed February 7, 2011. http://ec.europa.eu/education/languages/archive/doc/young_en.pdf.

Education Commission. 2004. Progress Report on the Education Reform (3). Hong Kong: Government Printer. Education and Manpower Bureau. 2003. A Final Report of Language Education Review. Hong Kong: Hong Kong Government Printer.

Li, David Chor Shing. 2009. “Towards 'Biliteracy and Trilingualism' in Hong Kong (SAR): Problems, Dilemmas and Stakeholders' Views.” In Multilingual, Globalising Asia Implications for Policy and Education AILA Review Vol 22, edited by Lisa Lim and Ee-Ling Low, 72-84. Amsterdam/Philadelphia: John Benjamins Publishing Company.

Lim, Audrey Swee Eng, and Yuen Ling Li. 2005. "Hong Kong Preschool Provisions for Early English Language Experiences: A Case for Redesigning Pedagogy.” Paper presented at the First International Conference on Educational Research on Redesigning Pedagogy: Research, Policy, Practice, Singapore, May 30-June 1.

Lu, Kwesting Zi Wen. 2010. "EFL Curriculum Development for Aged 2-8 Kids in Mainland China.” Paper presented at the International Conference on Teaching and Learning of English for Children in Early Years in the Asia-Pacific Region, Hong Kong, May 28-29.

Lu, Min Qiu. 2002. “淺談幼兒園的隻語教育” [A Brief Overview of the Bilingual Education in Mainland Kindergartens]. Guangxi jiao yu 廣西教育 15:39. (In Chinese)

Met, Myriam, and Nancy Rhodes. 1990. Elementary School Foreign Language Instruction: Priorities for the 1990s. Foreign Language Annals, 23(5): 433-443.

Moon, Jayne. 2005. "Teaching English to Young Learners: The Challenges and the Benefits." In English! Winter, 30-34. Accessed February 1, 2009. http://www.britishcouncil.org/ie2005w30-jayne-moon.pdf.

Nikolov, Marianna, and Helena Curtain, eds. 2000. An Early Start Young Learners and Modern Languages in Europe and Beyond. Strasborg: Council of Europe.

Pearson, Emma, and Nirmala Rao. 2006. "Early Childhood Education Policy Reform in Hong Kong: Challenges in Effecting Change in Practices." Childhood Education, 82(6): 363-368.

Rixon, Shelagh. 2000. "Optimum Age or Optimum Conditions? Issues Related to the Teaching of Languages to Primary Age Children.” Accessed January 10, 2009. www.britishcouncil.org/English/eyl/artcile01.htm.

Ruan, Wei. 2002. “英語族”的悲哀” [The Tragedy of the English Speaking Group]. Reading 讀書 12. Accessed February 8, 2011. http://www.wanfangdata.com.hk. (In Chinese)

Singleton, David. 2003. "Critical Period or General Age Factor(s)?" In Age and Acquisition of English as a Foreign Language, edited by María del Pilar García Mayo and María Luisa García Lecumberri, 3-22. Clevedon: Multilingual Matters. 
Tan, Li Hai, John A. Spinks, Guinevere F. Eden, Charles A. Perfetti, and Wai Ting Siok. 2005. "Reading Depends on Writing in Chinese." Proceedings of The National Academy of Sciences of the United States of America 102(24): 8781-8785, doi:10.1073/pnas.0503523102.

The Curriculum Development Council. 2004. English Language Curriculum Guide (Primary 1-6). Hong Kong: Hong Kong Government Printer.

The Curriculum Development Council. 2006. Guide to Pre-primary Curriculum. Hong Kong ; Hong Kong Government Printer.

Tsui, Amy Bik May. 2004. "Medium of Instruction in Hong Kong: One Country, Two Systems, Whose Language?" In Medium of Instruction Policies Which Agenda? Whose Agenda?, edited by James W. Tollefson and Amy Bik May Tsui, 97-116. Mahaw, NJ: Lawrence Erlbaum Associates, Pub.

Wu, Cynthia Hsin-Feng. 2007. "English as a second language in ECE: Policy, pedagogy and research." Paper presented at the $8^{\text {th }}$ Annual Conference of Pacific Early Childhood Education Research Association (PECERA), Hong Kong, July 4-7. 


\section{Appendix}

\section{Questionnaire on English learning at kindergarten}

\section{Serial no.}

This is a questionnaire about the English teaching in your school. It will take you about 10-15 minutes to complete. Please tick the suitable items or write numbers or write NA for items that are not applicable.

\section{Demographic Information}

1.1 Type of organization : $\square$ Private Independent

$$
\text { Non-profit making }
$$

1.2 Name of sponsoring body (if any)
1.3 No. of classes in each year: K1
$\mathrm{K} 2$
K3 $\square$

1.4 No. of teaching staff:

1.5 No. of staff taking up English teaching duties

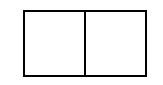

1.6 No. of students : AM session

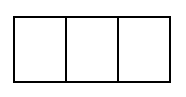

PM session

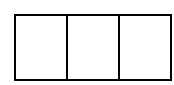

Full-day session

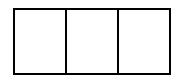

1.7 Years of teaching experience of Principal:

1.8 The highest qualification attained by the Principal:
$\square$ CE (ECE)
$\square$ BEd (ECE)
$\square$ Master (ECE)
$\square \mathrm{PhD}$ (ECE)

$\square$ Non $\mathrm{ECE} *$ certificate/degree/master $/ \mathrm{PhD}\left({ }^{*}\right.$ circle the right one)

$\square$ Others

1.9 The qualification will be attained by the Principal:
$\checkmark \mathrm{CE}$ (ECE)
BEd (ECE)
Master (ECE)
$\mathrm{PhD}(\mathrm{ECE})$
Non $\mathrm{ECE} *$ certificate/degree/master $/ \mathrm{PhD}(*$ circle the right one $)$
Others

1.9a Is there any international class in your school?

$\square$ Yes

$$
\text { No }
$$




\section{Appendix}

1.9b What is the mode of English teaching in the international class:

Immersion mode (using English as the main medium of instruction)

Bilingual mode (using half English and half Chinese as the medium of instruction)

Others

\section{The following questions are for non-international class}

\section{$\mathrm{K} 1$ refers to $3 \mathrm{yr}$ old group $\quad \mathrm{K} 2$ refers to $4 \mathrm{yr}$ old group $\quad \mathrm{K} 3$ refers to $5 \mathrm{yr}$ old group}

\section{Total time for English lessons:}

2.1 At which level(s) are English lessons offered? (Can tick more than one)
$\square \mathrm{K} 1$
$\square \mathrm{K} 2$
$\square \mathrm{K} 3$

2.2 For half-day sessions, how many minutes of English lessons are offered for each level per week?

K1

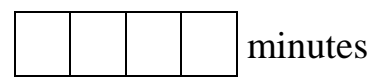

K2

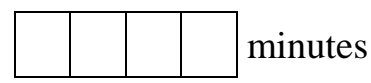

K3

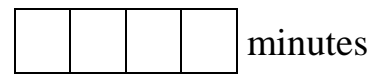

2.3 For whole day sessions, how many minutes of English lessons are offered for each level per week?

K1

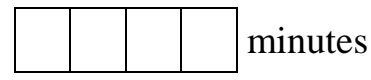

K2

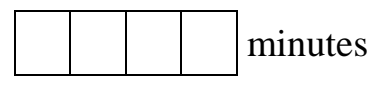

K3

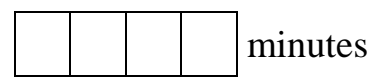

\section{K 3 Teacher-child ratio:}

The teacher-child ratio in K3 English class is:

AM class 1: $\square \quad$ PM class 1: $\square \quad$ Whole Day class : $\square$

Please use your K 3 whole day class as reference when answering Section IV and onwards. If your school does not have whole day class, then please use your K3 AM class as point of reference for answering the questions. 


\section{Appendix}

\section{IV: English teacher's profile and their numbers}

4.1 Who are taking up the English teaching duties for K3? : (Indicate the number in the brackets)

( ) Native English teachers from European countries e.g. UK, USA, Australia, NZ,etc .

( ) Foreign teachers using English as a second language from countries like India, Pakistan, Philippines, Thailand etc)

( ) Chinese returnees from overseas

( ) English major teacher from Mainland

( ) English major teacher from local university

( ) Local ECE teachers

( ) Others

4.2 What are their native tongues? :

( ) English as native language

( ) Fluent in English and Cantonese

( ) Chinese as native language

4.3 What are the qualifications of the teachers taking up English teaching duties?

( ) No training in ECE or TESL at all

( ) ECE trained (e.g. QKT/CE/BEd in ECE)

( )TESL/TEFL trained

( )With both ECE and TESL/TEFL qualifications

( )Other qualifications, please specify

4.4 How many of them have received other English teaching training?

( ) Have not received any English teaching training yet.

( ) Training course offered by SCOLAR

( ) Training course offered by sponsoring body

( ) Short term training course offered by CECESE

( ) Training by overseas organization

Others, please specify

4.5 What are their years of English teaching experience?

$\begin{array}{ll}(\quad) & 0-5 \text { year(s) } \\ (\quad & \text { ) } 6-10 \text { years } \\ ( & \text { ) } 11-5 \text { years } \\ (\quad & \text { ) } 16-20 \text { years } \\ (\quad & \text { ) } 20 \text { years or above }\end{array}$




\section{Appendix}

\section{Teaching Modes:}

5.1 Which of the following best describes the mode of English teaching of K3 class at present?

$\square$ Specialist mode :One English teacher (specialist) takes up the teaching of all classes.

$\square$ Combined mode :One English teacher (specialist) for each class plus a local teacher.

$\square$ Integrated mode :No specialist. The local class teacher takes up the teaching of English as well.

$\square$ Others

5.2 If you have ticked integrated mode in Q. 5.1, you can skip this question.

Referring to the specialist mode and the combined mode, how are the teaching duties divided between specialist English teacher and local class teacher?

$\square$ Specialist English teacher comes to school once or a few times a week, local class teacher takes up the remaining teaching using Chinese as the medium of instruction

$\square$ Specialist English teacher comes to school once or a few times a week, local class teacher takes up the English teaching for the rest of the week.

$\square$ Co-teaching between specialist English teacher and local class teacher. Local teacher takes care of the translation and looking after the homework.

Co-teaching between specialist English teacher and local class teacher. English teacher is responsible for English activities and local teacher is responsible for Chinese activities.

Other modes :

\section{VI: Curriculum}

6.1. Who makes decisions for the English curriculum? (Can tick more than one item)

$\square$ The English teacher

The curriculum teacher in school

The curriculum consultant of the sponsoring body

The principal/head teacher

Directly taken from publishers' teaching kit

$\square$ Others:

6.2 What are the difficulties encountered in planning the English curriculum?

Lack of professional support

English teacher not up to professional standard

English teacher is not ECE trained, cannot cater the needs of young children

Communication obstacles exist between teaching staff of varying English proficiency

Not enough teaching time

Lack of suitable teaching and learning materials

Cannot match with parents demands 


\section{Appendix}

Families of low SES cannot provide adequate language support at home

$\square$ No difficulty encountered

$\square$ Others

6.3. Is Putonghua taught also in $\mathrm{K} 3$ class?

$\square$ Yes

$\square$ No

6.4 If yes, how many minutes of PTH lessons there in a week?

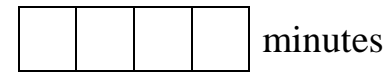

VII: English Materials (Can tick more than one items)

7.1 What English materials are used for K3 and the frequency of use?

\begin{tabular}{|l|l|l|l|l|}
\hline Types of teaching materials & Frequently & Sometimes & Seldom & Never \\
\hline Textbook & & & & \\
\hline Story books & & & & \\
\hline Worksheet/workbook & & & & \\
\hline $\begin{array}{l}\text { Phonic games (word cards, picture } \\
\text { cards) }\end{array}$ & & & & \\
\hline Puppets or 3D materials & & & & \\
\hline $\begin{array}{l}\text { CD of English nursery rhymes or } \\
\text { interactive CD-Rom }\end{array}$ & & & & \\
\hline Web resources & & & & \\
\hline \hline
\end{tabular}

7.2 Source of English teaching materials:

\begin{tabular}{|l|l|l|l|}
\hline Types of teaching materials & From publishers & $\begin{array}{l}\text { Self-developed by } \\
\text { teachers }\end{array}$ & $\begin{array}{l}\text { Developed by } \\
\text { educational unit of } \\
\text { the sponsors }\end{array}$ \\
\hline Textbook & & & \\
\hline Story books & & & \\
\hline Worksheet/workbook & & & \\
\hline $\begin{array}{l}\text { Phonic games (word cards, } \\
\text { picture cards) }\end{array}$ & & & \\
\hline Puppets or 3 D materials & & & \\
\hline $\begin{array}{l}\text { CD of English nursery } \\
\text { Rhymes or interactive } \\
\text { CD-Rom }\end{array}$ & & & \\
\hline
\end{tabular}




\section{Appendix}

7.3 How many English storybooks are there in school?

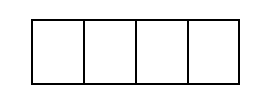

VIII: Learning activities and homework

8.1 Learning activities

\begin{tabular}{|l|l|l|l|l|l|}
\hline $\begin{array}{l}\text { What are the English } \\
\text { activities for K3? How often } \\
\text { is it done? }\end{array}$ & $\begin{array}{c}\text { Once a } \\
\text { month }\end{array}$ & Once a week & 2 or 3 times a week & 3 or 4 times a week & Daily \\
\hline Song singing & & & & & \\
\hline Reading aloud Eng. stories & & & & & \\
\hline Play language phonic games & & & & & \\
\hline Copy English vocabulary & & & & & \\
\hline Copy English sentences & & & & & \\
\hline Others & & & & & \\
\hline
\end{tabular}

8.2 What English homework will be given to the K3 children?

\begin{tabular}{|l|l|l|l|l|l|}
\hline $\begin{array}{l}\text { What are the English homework } \\
\text { for K3? How often is it done? }\end{array}$ & $\begin{array}{c}\text { Once } \\
\text { a } \\
\text { month }\end{array}$ & $\begin{array}{l}\text { Once a } \\
\text { week }\end{array}$ & 2 or 3 times a week & 3 or 4 times a week & Daily \\
\hline $\begin{array}{l}\text { Copying vocabularies and } \\
\text { sentences }\end{array}$ & & & & & \\
\hline Finish worksheets/workbooks & & & & & \\
\hline Reading aloud story book & & & & & \\
\hline Doing book report & & & & & \\
\hline Making story books & & & & & \\
\hline Others_ & & & & & \\
\hline
\end{tabular}




\section{Appendix}

8.3 Which of the following ways are children assessed on their English performance?

$\square$ Assessed regularly children's proficiency with tests and homework

$\square$ Count the number of books read by children

$\square$ Observe children's participation and interest in English activities e.g. story reading, singing songs, response to teacher's questions etc

$\square$ Document children's performance in the form of portfolio (collecting children's work)

Others

\section{IX: Learning environment}

9.1 Is there a separate English corner in the K3 classroom?

$\square$ Yes $\square$ No

9.2 If yes, what are the materials included in the corner? (Can choose more than one items)

$\begin{array}{ll}\square \text { Alphabet trains } & \square \text { Games boards } \\ \square \text { Rhymes and cassettes } & \square \text { Puppets } \\ \square \text { Posters } & \square \text { English calendars } \\ \square \text { English story books } & \square \text { English word cards } \\ \square \text { English dictionary } & \square \text { Others }\end{array}$




\section{Appendix}

9.3 How is the English corner used? (Can choose more than one item)

$\square$ For children's self learning

$\square$ A learning area for English activities

$\square$ For display of English materials

$\square$ For storage of English materials

$\square$ Others

9.4 How many times a week do children visit and spend their time at the corner?

Less than once in two weeks

Less than once a week

1 to 2 times per week

3 to 4 times per week

Every day

9.5 If there is not a separate English corner, where are the English learning materials and display located?

Language corner, together with the Chinese materials

A bilingual theme corner

$\square$ No show

$\square$ Others

\section{< End of questionnaire, thank you. >}

Please put the completed questionnaire into the self-addressed envelope and mail it back to me. Thank you. 